\title{
Manufacturing Performance Enhancement Through Various Maintenance Practices in Indian SMEs: A Literature Review
}

\author{
Simranjit Singh Sidhu ${ }^{1}$, Kanwarpreet Singh ${ }^{2}$ and I.P.S. Ahuja ${ }^{3}$ \\ Mechanical Engineering Department, Punjabi University, Patiala, Punjab, India \\ E-Mail: sidhu.simran28@gmail.com
}

\begin{abstract}
Globalization and liberalization of the world economy has leveled the field for all competitors around the globe. In this high competition environment all the industries try to lower the manufacturing cost of product and to increase their profit without compromising quality of product. Industries are in the race to search the ways to reduce the manufacturing cost of product. All over the world industries implement many techniques to sustain in this competitive world. In this environment Maintenance practices' become the essential and basic need of industries. The main objective of maintenance practices is to keep machines running all the time and increasing the availability of resources. Like this maintenance practices have become one of the most important functions in an organization. In India large industries implemented maintenance practices successfully and receiving their benefits. But a very little information is available regarding the success role of maintenance practices in small and medium enterprises. To face global competition successfully, SMEs have to successfully implement the maintenances practices. The purpose of this paper is to review the current scenario of various maintenance practices being implemented in SMEs. The paper will have great value for managers of SMEs in understanding the benefits accrued by implementing these maintenance practices. The paper will also cover the direct and indirect benefits of maintenance practices in Indian SMEs.
\end{abstract}

Keywords: Maintenance practices, SMEs and Manufacturing Performance

\section{INTRODUCTION}

Nowadays, Manufacturing Industries are facing challenge to increase their revenue due to very high competition all over the world.They want to produce very intense production of items to optimize revenue. Today is the epoch of globalization to increase revenue. Organizations have to compete with industries all over the world like in Japan, Korea and China etc. The manufacturing enterprises have taken in an excellent level of progress in the previous three decades, including extreme changes in administration methodologies, item and procedure advancements, consumer desires, supplier mentalities, and also due to very high competition.

The continuous process of identifying and eliminating the causes of inefficiency and ineffectiveness in business and production processes has, along with technical improvements, driven much of the increased standard of living. Hence, it is not surprising that most organizations quote problem-solving skills as a vital talent and require their people to sharpen their competencies in this area.

In the fast-changing market environment, slow and steady improvements in manufacturing operations do not guarantee sustained profitability or an organization's survival. In an increasingly global economy, cost-effective manufacturing has become a necessity to remain in the competition. The rapidly changing market requirements call for improvements in a company's performance by focusing on cost cutting, increasing productivity levels and quality and timely delivery to satisfy customers. Globalization has forced manufacturing organizations to produce their items with high caliber at a lower expense.

In the manufacturing industry, product quality has become a key factor in determining a firm's success or failure in the global market place. The major function of any manufacturing organization is to decrease the manufacturing cost of a part without compromising of its quality. To decrease manufacturing cost, is very important for any organization that depends on doing things with a superior method. It requires a non-stop search for options in each and every field to enhance execution prompting higher efficiency. So, to move forward in this dynamic world, each firm needs to make progress towards earning profit from all cycles of operations by using the assets like machine, men and material as ideally as possible.

The improvement of production quality is a commitment to continuous improvement in every aspect of the production process. Today's competitive market, in almost every category of products and services, is characterized by accelerating changes, innovation and massive amounts of new information. The increasing competition in the market creates a need to search new ways in which companies can differentiate themselves and gain more profit and better competitive position. Most of the industries want to become world-class organizations. For this, it is necessary for industriesto move toward modern development in all sectors.

\section{ENABLERS EFFECTING THE OVERALL PERFORMANCE IN SMES}

Everywhere throughout the world SMEs are judged as a spine of economic development. They contribute in giving work to various firms and act as a supplier of merchandise 
to huge associations. The rivalry among SMEs has definitely expanded in recent years so that to sustain of the SMEs in India has turned out to be extremely difficult. To contend in this constantly evolving environment, these SMEs must consider some cutting edge systems like consumer loyalty, worker strengthening, zero imperfection idea, zero breakdown, idea for working environment, and so forth [1].

Manufacturing organizations are applying different techniques for their survival in this tough competition, to increase their profit and productivity by reducing the manufacturing cost of parts. Manufacturing organizations are applying TPM, TQM, Kaizen, 5S, JIT, Kanban, Six Sigma and maintenance practices to increase the profit. Among these maintenance practices, some enablers areteamwork, predetermined planning, develop facts, worker training, inter functional training, employee involvement and committed leadership. These enablers are assumed to be major maintenance enablers in the successful implementation of maintenance [2]. As maintenance is the basic need of all organizations so, they have to apply this technique for increase their profit and productivity. Implementation of effective maintenance practices is the solution which includes every single idea talked here above [3].

\section{REQUIREMENT OF MAINTENANCE FUNCTION IN THE SMES}

The manufacturing maintenance is an important tool, which assumes basic part in an organization's capacity to contend on the premise of cost, quality and deliver execution of their planes $[4,5]$. The aim of the maintenance is to contribute towards a company's profit, as maintenance is the most required function that the organization should opt to attain pioneer position between their competitors [6]. Maintenance has become major budgetary variable at any organization, the cost of maintenance varies from 15 to $70 \%$ of total production cost [7]; [8].Maintenance has been a vital significance in manufacturing industries because company's internal effectiveness is strongly influenced by the maintenance role and impact on other working areas such as production, quality, production cost, working environment, amount of work-in-progress [9]. Maintenance also helps to increase the quality of production [10]. Qualityhas also turned into a key variable in deciding organization prosperity [11]. Manufacturing industries have constant pressure to increase their profit without compromising the quality, which have forcedorganizations to apply maintenance practices in their organization [12]. Therefore, maintenance practices became an integral part of organization without which, one cannot even think to increase the quality of a product because it is the basic need of an organization [13]. To attain quality,itsdemand to concentrate on apparatus this has brought maintenance outside of the meeting room of the organization [14]. The value of equipment is increased by increasing the life of equipment with the help of maintenances practices[15].
Maintenance plays a great role in increasing productivity [8]. In the event of a failure, whether small or big, the result is always loss in terms of money, time and life. These failures occur due to poor or no maintenance, therefore maintenance is necessary to cut back losses[16]. Effective maintenance that keeps life cycle prices down, not solely helps extending the life of a part, however contributes to the general performance of the corporate, maintenance improves system performance by enhancing system availability and reliability [17].

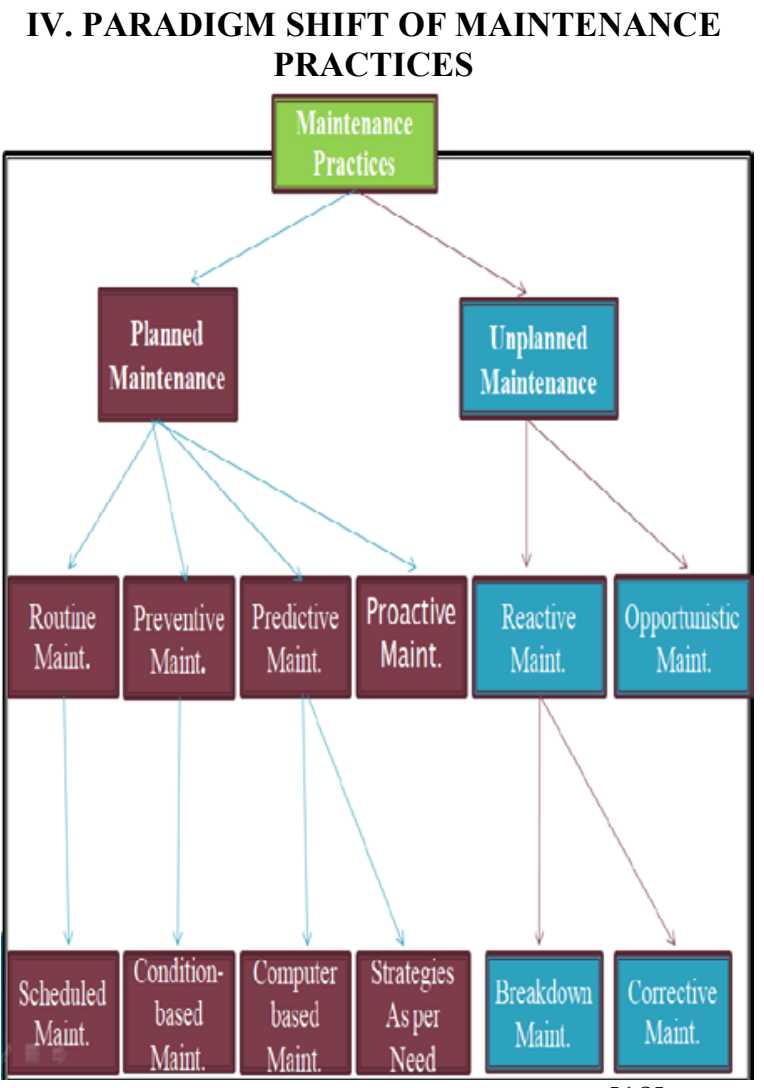

Fig. 1 Paradigm Shift of Maintenance Practices[18]

Basically maintenance practices are planned and unplanned maintenance further is can be classified into breakdown, preventive, predictive, corrective, computer based maintenance and proactive maintenance[19].

Due to globalization of manufacturing sectors, organizations have to innovate advanced technologies to fulfill the continuously changing needs of customer [13]. For this method for creation developments had changed quickly in the most recent three decades because of the execution of innovative production practices. In this scenario tackling producing problems have turned out to be more significant [20]. As worldwide market is in a condition of transition, power emergency have created anxiety in the worldwide market, as of now confronting turbulencedue to varying of development [21] and perspective of quality is conceivably changing from east to west [22]. 
It is recognized that production organizations should concentrate on improvement of quality of their production to survive in this tough competitive world. Maintenance practices have major role to increase the quality of an organization. It is a method for accomplishing world-class status to controlling organizations to enhance its overall effectiveness and performance [23], [24]. Maintenance practices have significant role in Quality Management (QM) in all the manufacturing organizations. It is likely to accomplish an extra business advantage in the course of maintenance practices in perspective of durable competitive benefit[25].

Maintenance practices play a critical role in an organization from all the advanced manufacturing technologies, with the increasing competition and complexity in production. The uses of Maintenance practices are turning out to be exceptionally good for an organization.Maintenance with its multifaceted exercises, assets, estimation and administration, has been critical to production. Because of the changing operational innovations, the part of supportmaintenance also increased to manage features of maintenance more efficiently. Maintenance related expenditure has increased due to the changing operational technologies and the role of maintenance has also increased in manufacturing industries [26].A study tells us that only one-third manufacturing industries are implementing the maintenance practices with full support to get the benefits of maintenance [27].This evoked researchers to investigate on these topics to innovate more extensive and creative execution of administration methodologies, for example, propositionScorecard and new authoritative upgrading apparatus [19]. The researchers have emphasized on role of maintenance practices in an industry to significantly enhance the availability and reliability of equipment [28].

In this way, a powerful maintenance system can make remarkable contributions to enhance availability and reliability of equipment to boost the manufacturing. Maintenance practices helps to ensure production efficiency and company's profit by creating parts at the mandatorycapacity and the required feature[5]. In the end, maintenance practices play indispensable part as far as worth included,quality improvement and to perform in this rising competition [29].

\section{ENHANCING ROLE OF VARIOUS MAINTENANCE FUNCTION IN SMES}

A small enterprise is an enterprise where the investment in plant and machinery is more than Rs.25 lakh but does not exceed Rs.5crore; and a medium enterprise is an enterprise here the investment in plant and is more than Rs.5 crore but does not exceed Rs.10 crore(Ministry of MSME, Government of India, 2010).

SMEs are defined by a number of factors and criteria, such as location, size, age, structure, organization, number of employees, sales volume, worth of assets, ownership through innovation and technology [31]. In manufacturing sector, SMEs act as specialist suppliers of parts, and subassemblies to large industries as these items can be produced cheaper than the companies could by themselves [32]. Usually due to lack of resources, SMEs may not have program for maintenance of equipment. Normally, SMEs outsource maintaining process to equipment service companies. Indian SMEs operate generally in an unsupportive environment [12]. Equipment maintenance was a low priority in most of the SMEs. Lack of knowledge about maintenance was one of the main hurdles, but due to very high competition and benefits of maintenance practices,SMEs are also implementing maintenance manufacturing in their organizations [33]

TABLE I DEFINITION OF SMALL AND MEDIUM ENTERPRISES IN INDIA: SOURCE: [39]

\begin{tabular}{|c|c|c|c|}
\hline Classification & Micro & Small & Medium \\
\hline $\begin{array}{c}\text { Manufacturing } \\
\text { Enterprises }\end{array}$ & $\begin{array}{c}\text { Rs. 2.5 } \\
\text { million/ Rs. } \\
\text { 25 lakh } \\
\text { (US\$ 50 }\end{array}$ & $\begin{array}{c}\text { Rs. 50 million// } \\
\text { Rs. 5 crore } \\
\text { (US\$ 1 } \\
\text { million) }\end{array}$ & $\begin{array}{c}\text { Rs. 100 } \\
\text { million/ Rs. } \\
10 \text { crore } \\
\text { (US\$ 2 } \\
\text { million) }\end{array}$ \\
\hline $\begin{array}{c}\text { Service } \\
\text { Enterprises }\end{array}$ & $\begin{array}{c}\text { Rs. 1 } \\
\text { million/ Rs. } \\
\text { (USh }\end{array}$ & $\begin{array}{c}\text { Rs. 20 million/ } \\
\text { Rs. 2 crore } \\
\text { (US\$ }\end{array}$ & $\begin{array}{c}\text { Rs. 50 } \\
\text { million/ Rs. 5 } \\
\text { crore (US\$ 1 } \\
\text { million) }\end{array}$ \\
\hline
\end{tabular}

Maintenance plays a vital role in SMEs. Thus, requirement seems clear and worldwide comprehension of maintenance manufacturing cooperates for the advantage of the entire organizations. One such view is presented by [34] (Figure 2),Maintenance is in the heart of the generation framework that is a piece of a worldwide venture.

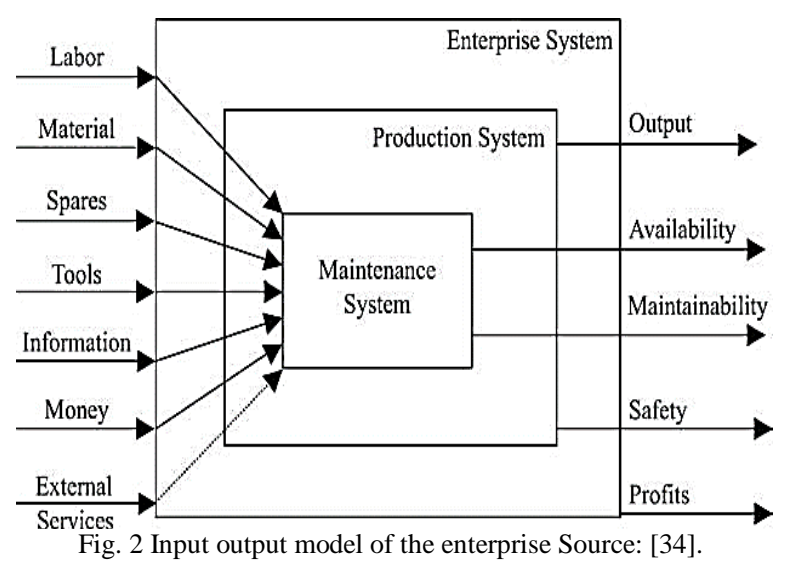

The achievement of the endeavor is exceptionally reliant on the yield of the generation framework as far as amount, quality, and security. Such yield can't be gotten without an exceptionally successful and proficient maintenance manufacturing that keeps up high rate of production equipment accessibility with long haul viability that keeps abnormal state of benefit worth [35]. Maintenance 
manufacturing provides arrangements and operations that ensures saves material, equipment, labour, money related assets available in the opportune time with the right quality and amount [36].

The fundamental motivation behind maintenance is to ensure that all equipment required for production, should be working at $100 \%$ effectiveness at all times [9]. Through short day by day reviews, cleaning, greasing up, and making minor conformities, minor issues can be distinguished and revised before they turn into a breakdown that can close down a generation line. A decent maintenance program requires broad investment and backing by everybody extending from the top official to the shop floor work force [37]. Maintenance is equally important for all industries weather it is large scale industry or it is a SMEs. Even more important in SMEs because SMEsare the heart of the large industries because large industries required and purchase most of the parts or component from small and medium size industries [30]. Everywhere throughout the world SMEs are judged as a spine of economic development [19]. SMEs are characterized by various components and criteria, for example area, size, age, structure, association, number of representatives, aggregate speculation, deals volume, and so on. SMEs need to benchmark themselves with the best in Industry [38]. The rivalry among SMEs has definitely expanded in recent years so that the continued existence of the SMEs in India has turned out to be extremely hard [32]. To contend in this constantly evolving environment, these SMEs have to implement such techniques those increase their productivity and reliability [31]. Maintenance manufacturing is the only solution to solve these problems, in which productivity and reliability of the organization is increased Those organizations that deliver results of high caliber at sensible expense will have the capacity to sustain in this competitive world [1].

\section{FACTORS FAVORING THE RESEARCH}

Today maintenance has become the basic need of every manufacturing organization. As it enhances production and reduces the creation cost of a product. However, it has been heralded as a major competitive weapon for manufacturing organizations operating in increasing competitive environments. Much of the literature review has revealed that various industries across the globe and in India have reaped benefits in business performance using effective maintenance practices.Moreover these benefits have the capability to provide organizations with continuous production without any failure. Current literature of Indian Industries has also revealed that maintenance practices are being holistically implemented by large Scale manufacturing industries whereas medium and small scale industries lacks in implementing these practices resulting in moderate enhancement of their performance measures,so there is an emergent need to examine the effectiveness of various maintenance practices for realizing improved business performance ofSMEs in India.

\section{REFERENCES}

[1] A.Jain, R. Bhatti and H. Singh, "Total productive maintenance No. TPM): a proposed model for Indian SMEs,"International Journal of Mechanical and Production Engineering Research and Development, Vol. 4, No.1, pp. 1-22,2014.

[2] R.Attri,et al., "An ISM approach for modelling the enablers in the implementation of Total Productive Maintenance (TPM),"International Journal of System Assurance Engineering and Management,Vol. 4, No. 4, pp. 313-326, 2013.

[3] T.Fasil and H. Osada, "Multiple dimensions of TQM success in developing countries: an empirical study on Deming Prize winners from India and Thailand,"International Journal of Innovation and Learning,Vol. 9, No. 2, pp. 184-203, 2011.

[4] L.Swanson, "An empirical study of the relationship between production technology and maintenance management,"International Journal of Production Economics, Vol. 53, No. 2, pp. 191-207, 1997.

[5] I.P.S. Ahuja and J.S. Khamba, "Assessment of contributions of successful TPM initiatives towards competitive manufacturing,"Journal of Quality in Maintenance Engineering, Vol. 14, No. 4, pp. 356-374, 2008.

[6] S.V.Amari, L. McLaughlin and H. Pham, "Cost-effective conditionbased maintenance using Markov decision processes,"Reliability and Maintainability Symposium, 2006. RAMS'06.. IEEE,Annual, 2006.

[7] G.Waeyenbergh and L. Pintelon, "Maintenance concept development: a case study,"International journal of production economics, Vol. 89, No. 3, pp. 395-405, 2004.

[8] M.Savsar, "Analysis and modeling of maintenance operations in the context of an oil filling plant," Journal of Manufacturing Technology Management,Vol. 22, No. 5, pp. 679-697, 2011.

[9] D.Maletič, et al., "The role of maintenance regarding improving produ Volumes,”Vol. 45, No. 31, pp. 7-12, 2012.

[10] B.Kirubakaran and M. Ilangkumaran, "The selection of optimum maintenance strategy based on ANP integrated with GRATOPSIS,"Journal for Global Business Advancement, Vol. 8, No. 2, pp. 190-215, 2015.

[11] M.Kaur, K. Singh and I. Singh Ahuja, "An evaluation of the synergic implementation of TQM and TPM paradigms on business performance,"International Journal of Productivity and Performance Management, Vol. 62, No. 1, pp. 66-84, 2012.

[12] A.Jain, et al., "Implementation of TPM for enhancing OEE of small scale industry,"International Journal of IT, Engineering and Applied Sciences Research,Vol. 1, No. 1, pp. 125-136, 2012.

[13] K.Singh and I.S. Ahuja, "Implementing TQM and TPM paradigms in Indian context: critical success factors and barriers,"International Journal of Technology, Policy and Management, Vol. 13, No. 3, pp. 226-244, 2013

[14] J.Lewis, "Eliminating defective product waste,"FDM (Des Plaines),Vol. 78, No. 13, pp. 73-76,2006.

[15] A.Salonen and M. Deleryd, "Cost of poor maintenance: A concept for maintenance performance improvement,"Journal of Quality in Maintenance Engineering, Vol. 17, No. 1, pp. 63-73, 2011.

[16] L.Wang, J. Chu and J. Wu, "Selection of optimum maintenance strategies based on a fuzzy analytic hierarchy process,"International journal of production economics, Vol. 107, No. 1, pp. 151-163, 2007.

[17] S.-H. Ding and S. Kamaruddin, "Maintenance policy optimizationliterature review and directions,"The International Journal of Advanced Manufacturing Technology, Vol. 76, No. 5-8, pp. 12631283, 2015.

[18] U.M.Al-Turki, et al., "Maintenance in manufacturing environment: an overview,"Integrated maintenance planning in manufacturing systems, Springer.pp. 5-23, 2014.

[19] A.Garg and S. Deshmukh, "Maintenance management: literature review and directions," Journal of quality in maintenance engineering,Vol. 12, No. 3, pp. 205-238,2006.

[20] J.J.Lawrence, "Use mathematical modeling to give your TPM implementation effort an extra boost,"Journal of Quality in Maintenance Engineering,Vol. 5, No. 1, pp. 62-69, 1999.

[21] S.Breja,D. Banwet and K. Iyer, "Role of flexibility in sustaining excellence: case of a TQM company,"International Journal of Productivity and Quality Management,”Vol. 5, No. 3, pp. 333-365, 2010. 
[22] J.J.Dahlgaard, et al., "Quality management practices: a comparative study between East and West,"International Journal of Quality \& Reliability Management,Vol. 15, No. 8/9, pp. 812-826, 1998.

[23] Z.Zhang, "Implementation of total quality management. An Empirical Study,” 2000.

[24] R.Chapman and K. Al-Khawaldeh, "TQM and labour productivity in Jordanian industrial companies,”The TQM magazine, Vol. 14, No. 4, pp. 248-262, 2002.

[25] O.Bayazit and B. Karpak, "An analytical network process-based framework for successful tota quality management (TQM): An assessment of Turkish manufacturing industry readiness,"International Journal of Production Economics,Vol. 105, No. 1, pp. 79-96, 2007.

[26] A.Parida and U. Kumar, "Maintenance perormance measurement (MPM): issues and challenges,"Journal of Quality in Maintenance Engineering,Vol. 12, No. 3, pp. 239-251, 2006.

[27] C.Cholasuke, R. Bhardwa and J. Antony, "The status of maintenance management in UK manufacturing organisations: results from a pilot survey,” Journal of Quality in Maintenance Engineering, Vol. 10, No. 1, pp. 5-15, 2004.

[28] R.Kodali, R. Prasad Mishra and G. Anand, "Justification of worldclass maintenance systems using analytic hierarchy constant sum method," Journal of Quality in Maintenance Engineering, 2009. Vol. 15, No. 1, pp. 47-77.

[29] G.Ghirardo, "Maintenance management in Italian manufacturing firms: Matters of size and matters of strategy,"Journal of Quality in Maintenance Engineering, Vol. 16, No. 2, pp. 156-180, 2010.

[30] A.Jain, R. Bhatti and H. Singh, "Total productive maintenance (TPM) implementation practice: A literature review and directions,"International Journal of Lean Six Sigma, Vol. 5, No. 3, pp. 293-323, 2014.
[31] S.U. Rahman, “A comparative study of TQM practice and organisational performance of SMEs with and without ISO 9000 certification,"International Journal of Quality \& Reliability Management, Vol. 18, No. 1, pp. 35-49, 2001.

[32] A.Sharma, G. Yadava and S. Deshmukh, "A literature review and future perspectives on maintenance optimization,"Journal of Quality in Maintenance Engineering,Vol. 17, No. 1, pp. 5-25, 2011.

[33] S.Ahmed, M. Hj. Hassan and Z. Taha, "State of implementation of TPM in SMIs: a survey study in Malaysia," Journal of Quality in Maintenance Engineering,Vol. 10, No. 2, pp. 93-106, 2004.

[34] U.Al-Turki, "A framework for strategic planning in maintenance,"Journal of Quality in Maintenance Engineering, Vol. 17, No. 2, pp. 150-162, 2011.

[35] V.Makis, "Optimal condition-based maintenance policy for a partially observable system with two sampling intervals,"The International Journal of Advanced Manufacturing Technology, Vol. 78, No. 5-8, pp. 795-805, 2015.

[36] S.-H.Ding and S. Kamaruddin, "Assessment of distance-based multiattribute group decision-making methods from a maintenance strategy perspective," Journal of Industrial Engineering International, Vol. 11, No. 1, pp. 73-85, 2015.

[37] D.Maletič, et al., "The role of maintenance in improving company's competitiveness and profitability: a case study in a textile company," Journal of Manufacturing Technology Management, Vol. 25, No. 4, pp. 441-456, 2014.

[38] B.S.MY, "Total productive maintenance: a study of Malaysian automotive SMEs," in Proceedings of the World Congress on Engineering, 2012.

[39] Annual Reports 2016-17, Government of India "ministry of micro , small and medium enterprises,"[Online] Available at: http://msme.gov.in/ 